Adam Felton - Ross A. Alford •

Annika M. Felton · Lin Schwarzkopf

\title{
Multiple mate choice criteria and the importance of age for male mating success in the microhylid frog, Cophixalus ornatus
}

Received: 23 January 2005 / Revised: 10 October 2005 / Accepted: 6 November 2005 / Published online: 11 January 2006

(C) Springer-Verlag 2006

\begin{abstract}
We examined multiple mate choice criteria in Cophixalus ornatus, a terrestrial breeding, microhylid frog. Mate choice consisted of three stages: mate attraction (male calling), courtship (male behavior between the call site and the nest), and nest site selection by the female. For male C. ornatus, the possession of a call with low dominant frequency relative to calling neighbors increased the probability that they would attract females. Dominant frequency was negatively correlated with age independent of male mass and snout vent length. When escorting the female from the call site to their nest, males traveled along more convoluted paths than when returning to the nest alone. The convolution of the path was, therefore, considered an aspect of courtship. Females released eggs into nests with structural characteristics typical of nests constructed by older males. Thus, females increased their chances of locating an acceptable nest by preferentially approaching males with lower dominant frequencies. This study is the first to demonstrate that age, independent of mass or snout-vent length, can influence call characteristics in anurans, and it is also the first to demonstrate the importance of male age to female mate choice in an amphibian.
\end{abstract}

Keywords Age $\cdot$ Microhylid frog $\cdot$ Mate choice Nest · Cophixalus ornatus

Communicated by J. Christensen-Dalsgaard

A. Felton $(\bowtie) \cdot$ R. A. Alford · L. Schwarzkopf

School of Tropical Biology, James Cook University, Townsville, Australia

e-mail: adamf@cres.anu.edu.au

Tel.: +61-2-61258131

Fax: +61-2-61250757

A. M. Felton

Centre for Resource and Environmental Studies,

W-K Hancock Bldg. (43),

Australian National University,

Canberra ACT 0200, Australia

\section{Introduction}

Our understanding of how male phenotypic qualities influence female mate choice typically comes from studies of mating systems in which males do not provide, or provide only limited levels, of resources in addition to gametes (Avery 1984; Duellman and Trueb 1994). This emphasis on non-resource-based mating systems is in stark contrast to the variety of mating systems observed in anurans (Duellman and Trueb 1994). Many anuran mating systems are 'resource-based' (Bourne 1997) involving males that provide resources to females in addition to gametes (Emlen and Oring 1977). These additional resources are often necessary for reproduction and include territories, nesting sites, food, or parental care (Gwynne 1984; Alatalo et al. 1986; Côté and Hunte 1989). Male mating success in these systems may be determined by female choice for both male phenotype and resource quality (Backwell and Passmore 1996).

With the exception of some members of the Dendrobatidae, the reproductive and mating behaviors of most terrestrial-breeding anurans are not well known (Zweifel 1985; Bourne 1997). Current understanding suggests that in general these frogs often provide extensive parental care to small numbers of large, terrestrial eggs (Duellman and Trueb 1994) that are oviposited into nest sites provided, or built, by the male (Townsend and Stewart 1994; Bourne 1997; Orlov 1997). Often associated with male provision of a nest site is male parental (paternal) care, during which time the male may stay with the eggs during part, or all, of the eggs' development (Crump 1995). While in attendance, adult males can protect the brood against predators (Simon 1983), desiccation (Forester 1984), fungal infestation (Forester 1979), and developmental abnormalities (Simon 1983).

In mating systems where reproductive success relies on male provision of nest sites and parental care, females can select a partner using aspects of the male phenotype that are indicative of the male's ability to provide these resources (Balmford et al. 1992). Phenotypic indicators of a male's potential quality as a parent should therefore be a major component of female mate choice criteria in these mating systems. We examined the factors influencing female mate 
choice in the terrestrial-breeding ornate nursery frog Cophixalus ornatus Fry 1912. In this species, males attract females by calling from within a chorus, provide females with oviposition sites, and then with paternal care for direct-developing eggs (Zweifel 1985). These three aspects of male mating behavior allow us to divide female mate choice in $C$. ornatus into three distinct stages.

Firstly, we examined what quality or combination of qualities of the male's advertisement call influences female choice for a particular male within the chorus and measured male age to determine whether it correlated with male size and call characteristics. Low dominant frequency (Forester and Lykens 1986; Robertson 1986; Morris and Yoon 1989), high rates of calling (Arak 1988; Morris 1989; Lopez and Narins 1991), high sound pressure levels (Arak 1988), and/ or calls of longer duration (Gerhardt 1991; Kasuya et al. 1997) are all typically attractive features of calls. In many studies, one or all of the acoustic components preferred by females are correlated with male size (Sullivan 1983; Ryan 1985; Arak 1988; Robertson 1990; Passmore et al. 1992). Although body size in frogs is also positively correlated with male age (Duellman and Trueb 1994) and there are theoretical arguments for why older males should make more attractive mates (Kokko 1997; Clutton-Brock et al. 1988), no studies have correlated anuran vocal display features and male age, independent of size (Lykens and Forester 1987; Johnstone 1995).

Secondly, we assessed whether there were quantifiable differences in male behavior when males traveled to the nest from the call site with and without a female, a behavior referred to in other species as 'courtship leading' (Summers 1992) or 'pre-ampletic courtship' (Townsend and Stewart 1986). Finally, we compared the characteristics of nests accepted and rejected by females. As nest characteristics are likely to be directly related to offspring survival and therefore female fitness (Jones and Reynolds 1999), nest sites are likely to be an important factor influencing female choice in this species. In addition, we examined the phenotypic characteristics of males with accepted versus rejected nests and determined whether the male phenotype or age may be indicative of their egg attendance rates.

\section{Methods}

Study site and field methods

C. ornatus is found in moist rainforests of coastal and adjacent ranges of northeast Queensland, Australia, and is distributed from the Paluma Range to Mount Carbine Tableland from sea level to 1,540 $\mathrm{m}$ (McDonald 1991). The study site was located in simple notophyll vine forest surrounding Paluma township (latitude, $19^{\circ} 00^{\prime} \mathrm{S}$; longitude, $146^{\circ} 13^{\prime} \mathrm{E}$; approximately $980 \mathrm{~m}$ above sea level; McDonald 1991). Mean annual rainfall at Paluma is $2,850 \mathrm{~mm}$, with annual mean temperatures between 19 and $21^{\circ} \mathrm{C}$ (McDonald 1991).

Field observations were conducted between September 1998 and February 1999. Behavioral observations and mark-recapture studies began at dusk (19:00) and continued until males ceased calling (approximately 04:00). Males were located by their advertisement call, whereas females, immatures, and noncalling males were located opportunistically. Males were examined to determine whether they were marked, if they were, the area around them was carefully scrutinized for females approaching in response to their call. Unmarked males were captured and toe-clipped for future identification (Heyer et al. 1994), and toes were stored in $70 \%$ ethanol for use in aging analysis. Individuals were weighed to the nearest $0.1 \mathrm{~g}$. Snout-vent length (SVL) was measured to the nearest $0.1 \mathrm{~mm}$. Individuals were returned to their place of capture after measuring was completed, and they usually resumed calling within approximately $10 \mathrm{~min}$. We recorded 12 successive calls for males each evening onto a Sony TCM5000 recorder using a Sennheiser shotgun microphone. Recordings were limited to one side of a cassette to avoid possible 'tape bleed' (Heyer et al. 1994).

When a female was found within close proximity to a calling male, we stopped visiting other males' calling sites and remained quietly observing the female from a distance of $2 \mathrm{~m}$ using a dim light fitted with a red filter. Unmarked females were not marked until it was obvious they were not going to respond to the male's call or until mating and egg deposition was complete. When approached by a female, the male's call became audibly distinguishable from the advertisement call. These calls, henceforth referred to as courtship calls, were also recorded. The time of observation and position of the male and female when first observed were recorded. We measured the path taken by the male when leading the female to the male's nest by placing small markers along their path and subsequently recording the compass directions and distances between each point at which the male stopped. The path taken by these males when unaccompanied and the shortest possible path between the call site base and the nest entrance were also measured.

Nests were defined as accepted if they contained eggs and rejected if not. Accepted nests were checked twice daily during the early afternoon and late evening to assess male attendance. Monitoring continued until the eggs hatched or were lost to predation, desiccation, or fungal infestation. On days when males were absent, egg number and nest characteristics were recorded. Material used to construct the nest's roof, walls, and floor was classified based on the most abundant material used: leaves, mud, wood, or rock. The following nest dimensions were measured to the nearest $0.5 \mathrm{~cm}$ : nest depth (entrance point to the deepest point), chamber size (longest dimension of chamber $\times$ longest perpendicular dimension), nest roundness (longest chamber dimension/shortest chamber dimension), and entrance width.

\section{Analysis of male age}

Skeletochronology was used to age male $C$. ornatus. Toes were placed in $10 \%$ formic acid for $5 \mathrm{~h}$ to demineralize tissues as a softening technique prior to sectioning. This process was completed when Arnim's test indicated that 
there was no residual calcium oxalate in the decalcifying solution. After blocks were embedded in paraffin, they were placed in $10 \% \mathrm{NH}_{4}$ solution for at least $1 \mathrm{~h}$ to further soften tissue. Blocks were serially sectioned at $8 \mu \mathrm{m}$ and mounted, dried, and stained using Ehrlich's hematoxylin for $20 \mathrm{~min}$, Scott's tap water for $30 \mathrm{~s}$, and Young's Eosin stain for $3 \mathrm{~s}$.

The age of each frog was estimated by three people who independently counted the number of lines of arrested growth (LAGs) present in the toe sections, without considering the outer margin of the bone as a LAG. Confirmation that each growth layer and LAG were formed annually was obtained by counting LAGs in toe clips taken from three C. ornatus in 1995-1996 and then recaptured in 1998-1999. As toes used for aging were the biproducts of identification, using a standard digit for all individuals was not possible. To ensure that this would not affect the results, four different phalanges from each limb of a single individual were aged in a blind test to ensure that readings were consistent for individuals regardless of the digit taken.

\section{Analysis of calls}

For each male, three calls were selected from the beginning, middle, and end of the recording. Call rate (number of calls per unit time), call length (time from first pulse of call to last), pulse rate (pulses/ms), and dominant frequency [peak amplitude frequency within the call $(\mathrm{kHz})$ ] were assessed using Avisoft SAS lab Pro 3.0. A sampling frequency of $44,100 \mathrm{~Hz}$, FFT of 1,024, and a sample size of 16 bits were used. We used the Hamming window format to suppress spectral leakage (Avisoft Bioacoustics 1999). To determine the call characteristics attractive to females, we compared the calls of males that successfully attracted females with those of their nearest calling neighbor recorded on the same night. Statistical comparisons were only made if we had recordings from both males on the night the female was attracted. This avoided possible confounding of results due to between-night variations in individual male call characteristics (Brooke et al. 2000).

\section{Statistical analysis}

Spearman rank correlations were carried out using SPSS version 8 for Windows (SPSS Inc. 1997). Unless otherwise indicated, all other statistical tests were carried out using StatXact 4 for Windows (CYTEL Software Corporation 1999).

Stage 1-attracting a female using call characteristics We defined a male as attractive at this stage of mating if he was observed successfully attracting a female to his call site. We tested whether size assortative mating occurred using Spearman rank correlations to analyze the SVL of females and the males to whom they were attracted. The SVL and age of the attractive male and his nearest neighbor were compared using a Wilcoxon signed-ranks test. A multivariate extension of the Wilcoxon matched-pair signed-rank test (Alford 1999) was used to test whether the call characteristics of attractive males differed significantly from those of unattractive males. The relative contribution of each call component (call rate, call length, pulse rate, and dominant frequency) was determined using the Wilcoxon signed-rank tests applied to each call component. We compared call frequency distributions of attractive and unattractive males using recordings of 23 males made over three consecutive nights with similar mean temperature with a Wilcoxon-Mann-Whitney $U$ test.

Spearman rank correlations were used to determine the relationship between male dominant frequency and male SVL. To assess whether male age, independent of size (SVL or mass), correlated with call dominant frequency, we used partial correlation analysis of male calls recorded during a single week. We used Spearman rank correlations to determine whether there was a relationship between age and SVL of males.

Stage 2-courtship calling and following Courtship call characteristics and courtship path convolution were examined to assess the reason why females were attracted. To determine if there was a significant difference between male advertisement calls and courtship calls, we used RAMANOVA Ver. 1.48 (Alford 1999). This program determines the probability of differences as great as or greater than those observed among treatments by comparing the sums of the squared Euclidean distances from each observation to its treatment centroid to an empirical distribution. The empirical distribution is obtained by repeatedly randomly assigning observations to treatments, without replacement, and calculating the value of the test statistic. Randomizations were set at 200,000 with outcomes only accepted as significant if the upper $99 \%$ confidence limit for $P$ is less than 0.05 . We then determined which call characteristics (standardized values of dominant frequency, call length, and pulse rate) differed significantly between advertisement and courtship calls using Wilcoxon-Mann-Whitney $U$ tests.

We compared the straightness of the males' path when accompanied by females [straightness was determined by dividing the length of the shortest possible path in centimeters (the straight line distance from the calling site to the nest) by the length of the courtship path in centimeters] with the straightness of his path when returning alone to the nest (calculated by dividing the length of the shortest possible path by the length of the path of the lone male). Straightness was determined for 9 courtship paths and 11 paths of lone males using the Wilcoxon-Mann-Whitney $U$ tests. The same test was used to determine if the straightness of the courtship path influenced mating success (the probability of successful oviposition by females).

We examined the correlation between the courtship path length and the straight line distance between the nest and the calling site, because there are three possible ways that courtship leading may function. First, males may simply lead females to the nest. In that case, there should be a 
positive correlation between the nest-to-calling site distance and the distance the male leads the female. Second, there may be some minimum courtship following distance or time required to maintain female interest, in this case, males with nearby nests would take females on long journeys, and there would be a negative correlation between the distance from the nest to the calling site and the courtship path length. Finally, individual males may simply differ in the distance or time that they lead females, hence in this case, we expect no correlation between nest-to-calling site distance and leading distance. We used Spearman Rank correlations to test these hypotheses.

Stage 3-nest site characteristics We defined a male as successful at this stage if the female oviposited eggs in the male's nest. To determine if there were significant differences between the nest characteristics (standardized values of nest depth, chamber size, nest roundness, entrance width, material used; see "Methods") of accepted nests and rejected nests, we used RAMANOVA Ver. 1.48 (Alford 1999) set at 200,000 randomizations. The means of these standardized values were tested for significance using the Wilcoxon-Mann-Whitney $U$ tests.

To determine if there were differences between nests provided by young or old males, we also used RAMANOVA Ver. 1.48 (Alford 1999). The means of these standardized values were tested for significance using the Wilcoxon-Mann-Whitney $U$ tests. Young males ranged from 4 to 6 years and old males from 7 to 9 years. These age categories were chosen because they were divided at the median age (6 years) of males who lead females to their nest. The same statistical procedure was used to assess differences between nests provided by small and large males. Males were categorized as small if they were $\leq 2.12 \mathrm{~cm}$ and large if they were $\geq 2.13 \mathrm{~cm}$. These categories were chosen because they fell on either side of the mean SVL $(2.12 \mathrm{~cm} \pm 0.01)$ for males who lead females to their nest.
Fate of nests Relationships between egg attendance rates of males (percentage of nest observations at which males were present) and male age, SVL, mass, and condition (SVL/mass) were tested using Spearman rank correlations. We determined whether egg attendance rate and male age were related to clutch mortality using the WilcoxonMann-Whitney $U$ tests.

\section{Results}

Courtship and mating behavior

Males called from August to March, during the wet season. Males called from perches in trees, shrubs, epiphytes, and forest debris located from 0 to $200 \mathrm{~cm}$ above ground (mean $66.41 \mathrm{~cm} \pm 1.98 \mathrm{SD}$ ). In general, males called facing away from the substrate.

Forty-one mating interactions were observed, from the female's first contact with a male at the calling site up to her departure from the male's nest. We have combined these observations to describe a "typical" encounter between a male and a female. When the female approached the male at the call site, the male acknowledged the female's presence by backing down from the call site to the ground and altering his advertisement call to a courtship call (Fig. 1). If neither of these responses was elicited by her presence, the female made contact with the male, usually by bumping into his hind limbs or tapping him with a forelimb.

After the male reached the ground, he paused after moving a small distance $(<10 \mathrm{~cm})$. During the pause, the male produced courtship calls that continued until the female responded by moving closer to the male. Once the female closed the distance between them, the male hopped or crawled another short distance away, paused and began calling again. Courtship calls produced during each waiting period varied from barely audible to approximately $60 \mathrm{~dB}$, increasing in loudness as the time the female took to approach
Fig. 1 Waveform (above) and spectrogram (below) of a $C$. ornatus advertisement call (left), followed by a courtship call (right) recorded from the same male on the same night. $k U$ kilounits, $k H z$ kilohertz, $S$ seconds

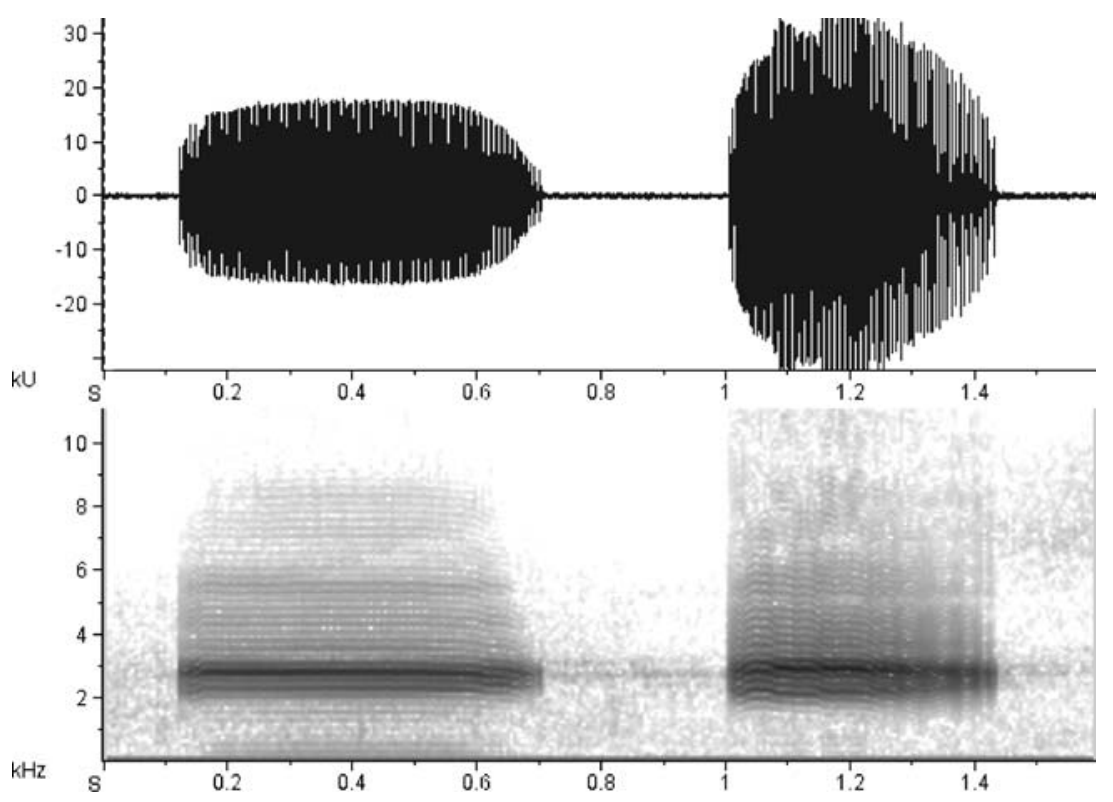


Table 1 SVL and mass for adult male and female $C$. ornatus

\begin{tabular}{|c|c|c|c|c|}
\hline & \multicolumn{2}{|l|}{ SVL (mm) } & \multicolumn{2}{|l|}{ Mass (g) } \\
\hline & Range $(n)$ & Mean(SD) & Range (n) & Mean (SD) \\
\hline Adult male & $16-25(25)$ & $20.1( \pm 1.7)$ & $0.75-1.6(31)$ & $1.04( \pm 0.14)$ \\
\hline $\begin{array}{l}\text { Adult } \\
\text { female }\end{array}$ & $21.9-27.2(25)$ & $24.2( \pm 1.6)$ & $1.0-1.9(27)$ & $1.45( \pm 0.30)$ \\
\hline
\end{tabular}

him increased. The male led the female on a convoluted path to his nest site, and on average, this journey took over an hour to complete (76 $\mathrm{min}, n=41, \mathrm{SD} \pm 23$ ) and covered up to $350 \mathrm{~cm}$. On average, nests were $112.6 \mathrm{~cm}$ (range $0-378 \mathrm{~cm}$, $n=41, \mathrm{SD} \pm 78.7$ ) from the male's calling site. When the male was within approximately $5 \mathrm{~cm}$ of his nest site, he ceased making the courtship call and began to walk with slow limb movements punctuated by repeated stops in midmotion. The male walked this way into the nest entrance. Out of view, the male began the courtship call again until the female entered the nest.

Nests had a mean chamber width of $3.53 \mathrm{~cm}(n=21, \mathrm{SD} \pm$ $1.03)$, were $3.1 \mathrm{~cm}$ deep $(n=21, \mathrm{SD} \pm 1.93)$, and the majority of nests had floors and walls of mud and a roof of leaves. Nests were also found in rotting logs, tree roots, and mosscovered stone walls. We did not observe either males or females building or modifying nests.

Twelve hours after entering the nest, the majority of females (39 of 41) had left, although one female remained in a male's nest for 6 days before ovipositing. On three occasions, males were observed to call from within the nest while females were vacating the nest site. Subsequent assessment revealed that these females had not oviposited. The average nest contained 1.5 clutches $(n=27, \mathrm{SD} \pm 0.7)$. Females laid a single strand of 3 to 22 eggs (mean 14 eggs, $\mathrm{SD} \pm 3.64)$. One female visited three different nests provided by three different males over a period of 10 days without laying eggs in any of them. Two males were observed to use two nests concurrently, with eggs present in both nests. One male frequented three nests over the course of the season.

Eggs hatched in 4 to 6 weeks. Once hatched, the young dispersed from the nest over a period of 2 to 3 days. Egg clutches were found from September to February.

\section{Size and age}

Males were smaller and lighter than females, on average, although both length and mass ranges overlapped for males and females (Table 1). Conclusions regarding the age of an individual were consistent regardless of which digit was used in the age analysis. Forty-one males were aged using skeletochronology. Comparing the LAGs within an individual among years revealed that LAGs were annual. Adult males were on average 5.5 years of age $(n=41, \mathrm{SD} \pm$ 2.1). Breeding males ranged from 4 to 14 years of age. Male age was not significantly correlated with SVL for males of breeding age $(n=35, P=0.6$, correlation coefficient $=-0.08$; Fig. 2).

\section{Mate choice: stage 1}

There was a significant difference between the calls of attractive males and nonattractive neighbors for the six call characteristics measured (multivariate extension of Wilcoxon matched-pairs signed-rank test, two-tailed, $n=12, P=0.025$ ). When females approached one of two adjacent calling males, they chose the male with a lower dominant frequency call ( $n=12$, attractive males mean $2,894 \mathrm{~Hz} \pm \mathrm{SD} 117$, unattractive males mean 3,282 Hz $\pm \mathrm{SD} 169, P=0.03$; Fig. 3). Larger
Fig. 2 The relationship between body size $(S V L)$ and age (number of annual rings in a toe section) in a sample of 41 male C.ornatus. Breeding males ranged from 4 to 14 years of age. Open circles represent newborn individuals

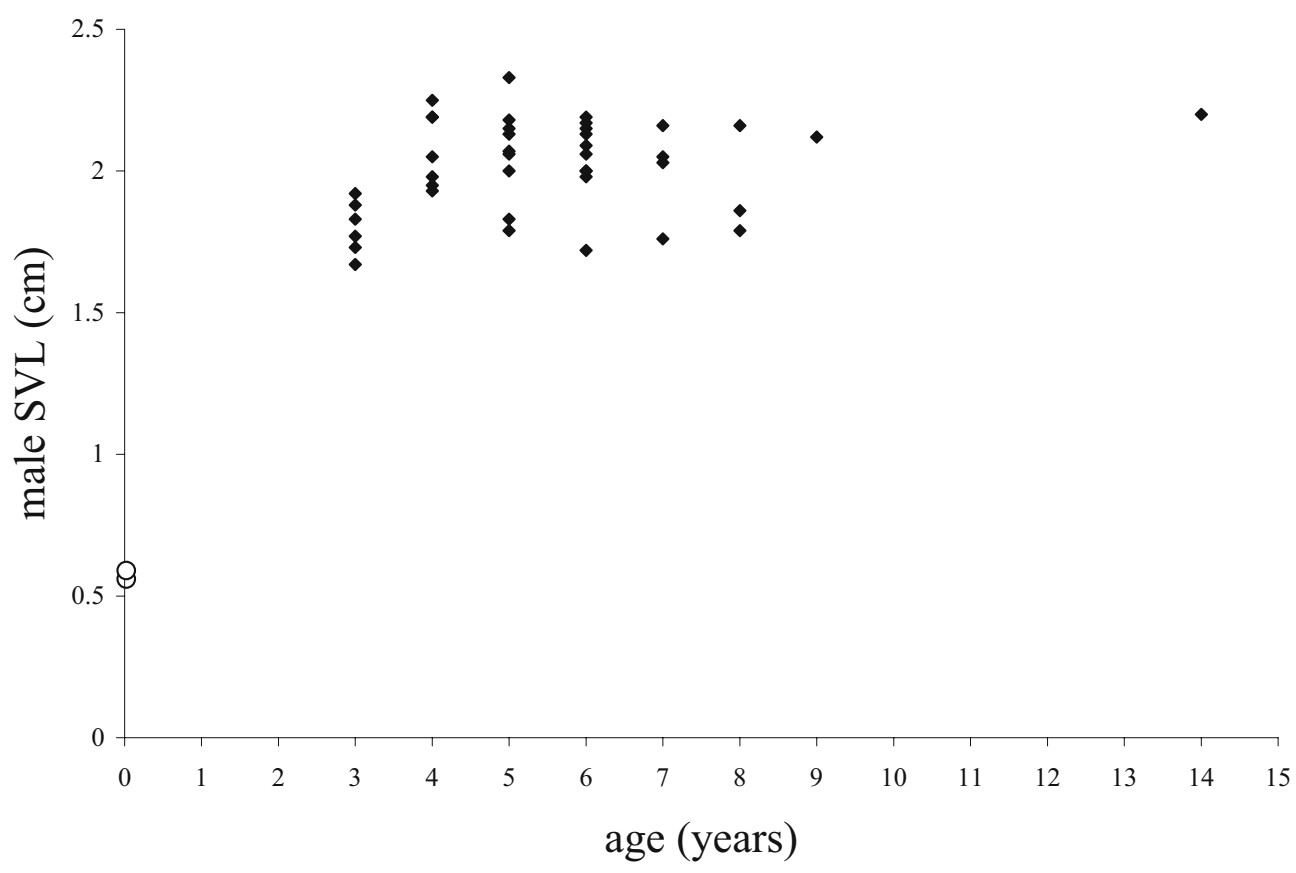


males (SVL) had lower dominant call frequencies $(n=43, R=$ $-0.7, P<0.001)$. No significant difference was found in call length $(n=12, P=0.4)$, decibel level $(n=12, P=0.06)$, pulse rate $(n=12, P=0.3)$, pulse per call $(n=12, P=0.2)$, and call rate $(n=12, P=0.2)$ between males that successfully attracted females and their unsuccessful neighbor. There was also no significant relationship between male size (SVL) and female size in mating pairs of this species $(n=25, P=0.5)$.

Attractive males were significantly larger than their nonattractive neighbors $(n=12, z=-3.4, P=0.03)$. Furthermore, male age was negatively correlated with call dominant frequency when controlling for male SVL ( $n=41, r=-0.3, P=0.045$, partial correlation coefficient -0.32 ) and male mass $(n=41, r=-0.4, P=0.013$, partial correlation coefficient -0.4 ). The call dominant frequencies of attractive males were not significantly different from males from the general population that were not known to attract females $(n=23, z=-1.449, P=0.16)$.

Mate choice: stage 2

Overall, call characteristics of courtship calls were significantly different from advertisement calls (RAMANOVA $n=14, P=0.02$; Table 2, see also Fig. 1). Of the call components used in this analysis, dominant frequency was significantly lower in courtship calls $(n=14, P<0.001)$, but other call components did not differ significantly.

No females terminated the courtship while being led back to the nest. When females accompanied males, males took a significantly more convoluted path to the nest site than when they returned to their nest sites alone $(n=20$, with females mean straightness $0.56, \mathrm{SD} \pm 0.4$; alone mean straightness $0.85, \mathrm{SD} \pm 0.27 ; z=-2.282, P=0.019)$. The convolution of the courtship path taken by males who successfully mated was similar to males that were unsuccessful ( $n=9$, successful mean straightness $0.58, \mathrm{SD} \pm 0.36$; unsuccessful mean straightness $0.53, \mathrm{SD} \pm 0.51$; one-tailed $P=0.4$ ). When the distance between the nest and the call site was long, convolution was relatively low, whereas when distance was short, convolution was higher $(n=9$, one-tailed $P=0.031$; Fig. 4). The variance for the distance of the path taken by males with females and the variance for the straight line distance from the calling site to the nest were not significantly different $(n=9, F=3.01, P>0.1)$.

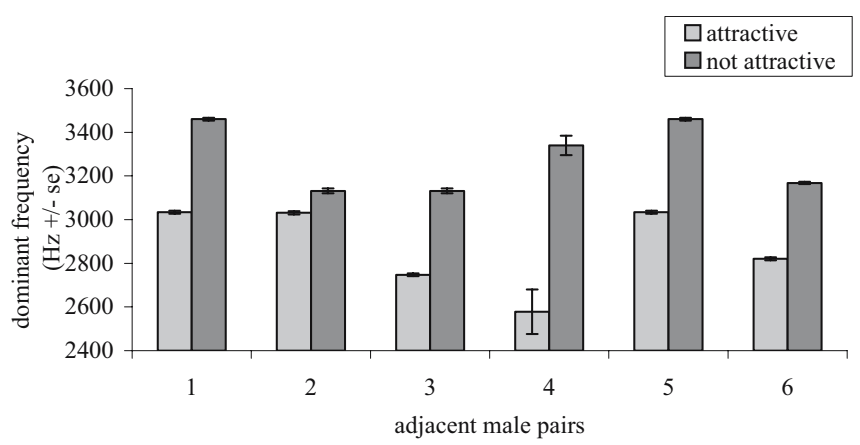

Fig. 3 Comparison of male call dominant frequency between successful and unsuccessful adjacent $C$. ornatus males
Table 2 Call characteristics of $C$. ornatus advertisement and courtship calls $( \pm \mathrm{SD})$

\begin{tabular}{lcccc}
\hline & $\begin{array}{l}\text { Dominant } \\
\text { frequency }(\mathrm{Hz})\end{array}$ & $\begin{array}{l}\text { Call } \\
\text { length } \\
(\mathrm{s})\end{array}$ & $\begin{array}{l}\text { Pulse rate } \\
(\text { pulses} / \mathrm{s})\end{array}$ & $\begin{array}{l}\text { Decibels } \\
(\mathrm{dB})\end{array}$ \\
\hline $\begin{array}{l}\text { Advertisement } \\
\text { call }(n=41)\end{array}$ & $\begin{array}{c}( \pm 974.61 \\
( \pm 177.24)\end{array}$ & $\begin{array}{c}0.48 \\
( \pm 0.06)\end{array}$ & $\begin{array}{c}242.70 \\
( \pm 33.28)\end{array}$ & $\begin{array}{c}83.21 \\
( \pm 5.06)\end{array}$ \\
$\begin{array}{l}\text { Courtship call } \\
(n=7)\end{array}$ & $\begin{array}{c}2,629.87 \\
( \pm 187.06)\end{array}$ & $\begin{array}{c}0.39 \\
( \pm 0.03)\end{array}$ & $\begin{array}{c}254.36 \\
( \pm 25.52)\end{array}$ & $<50$ \\
\hline
\end{tabular}

Mate choice: stage 3

The characteristics of accepted and rejected nests were also significantly different (RAMANOVA $n=18, P=0.03$ ). Of the measured nest characteristics, the possession of mud or wood walls $(P=0.003)$, increased depth $(P=0.005)$, small nest mean size $(P=0.03)$, and an elongated nest chamber $(P=0.02)$ contributed significantly to nest acceptance by the female.

The nest characteristics of small and large males were similar $(n=17, P=0.5$ ), but the nests of old and young males differed significantly $(n=17, P=0.049)$. The nests of old males were significantly more likely to have mud floors $(P=0.04)$, an elongated nest chamber $(P=0.045)$, and walls made of mud or wood $(P=0.047)$ compared to those of young males.

Fate of nests and paternal behavior

Of 23 monitored nests containing eggs, 10 experienced clutch mortality. In three nests, eggs were depredated by invertebrates (centipede, carabid beetle, ants), one nest was damaged by an unknown source, two clutches were lost to fungal infestation, and four disappeared. Egg cannibalism was not observed. All males adopted a posture in the nest that increased ventral body contact with the eggs, and three males lunged at objects inserted into their nest.

On average, males attended to the eggs $50 \%$ of the time $(n=21, \mathrm{SD} \pm 27 \%$, range $5-88 \%$ ). Clutch attendance rates by males were not correlated with male age $(n=20, P=0.8)$, male SVL $(n=20, P=0.5)$, male mass $(n=20, P=0.9)$, or male condition $(n=20, P=0.623)$. Egg mortality over the entire season was not related to egg attendance (WilcoxonMann-Whitney $U$ test $n=13, P=0.5$ ). There was no relationship between male age and clutch mortality rates (Wilcoxon-Mann-Whitney $U$ test $n=21, P=0.64$ ). Clutch mortality due to dehydration or fungal infestation was only observed after males had abandoned the nest.

\section{Discussion}

In terrestrial-breeding frogs with nests and parental care provided by males, female mating decisions are based on a hierarchical series of decisions, in which different selection 
Fig. 4 The relationship between path convolution during courtship [courtship distance/ shortest possible route $(\mathrm{cm})]$ and the shortest route $(\mathrm{cm})$ possible taken by $C$. ornatus males from the call site to the nest

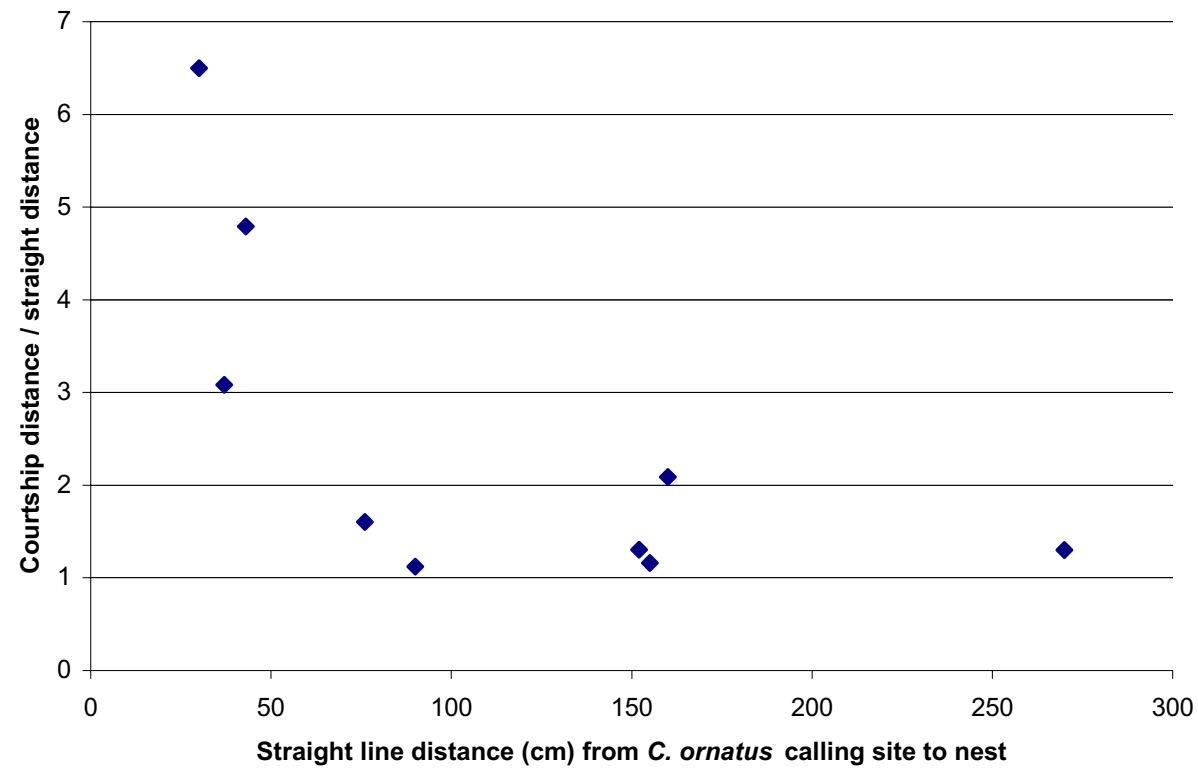

criteria are weighed relative to the fitness benefits received from each (Barlow 1992). For example, among potential mates, the male providing the best combination of genetic quality, paternal care, and breeding site may be chosen by the female. However, the relative contribution that each trait or resource makes to male mating success is likely to vary depending on the mating system and environmental circumstances at the time (Johnstone 1995).

Male mating success in C. ornatus relies on three distinct stages of mating behavior. Firstly, males need to attract females to their call site using advertisement calls. Secondly, males need to successfully lead the female using courtship calls to the nest. Thirdly, males need to provide nests that females accept for oviposition. Males lacking the phenotypic or resource requirements necessary to succeed at any stage will not mate.

The first opportunity for female $C$. ornatus to exhibit mate choice is similar to non-resource-based mating systems in which female selection of males is based on vocal displays (Sullivan et al. 1995). Like many other anurans (Ryan 1980, 1983; Forester and Czarnowsky 1985; Robertson 1986), female C. ornatus prefer calls with low dominant frequency. Larger male frogs produce calls with relatively lower dominant frequency (Ryan 1985; Morris and Yoon 1989; Arak 1988; Robertson 1990), because the size of the vocal apparatus is correlated with male size, and larger voice boxes make calls with a lower dominant frequency (Duellman and Trueb 1994). Female choice for calls with lower dominant frequency results indirectly, therefore, in choice for larger males.

Although anurans typically continue to grow throughout their lives, growth often slows greatly after sexual maturity (Platz and Lathrop 1993) and depends on the environmental conditions experienced by individuals (Duellman and Trueb 1994). Because of this, differences in size among adults are often only loosely correlated with differences in age (Halliday and Verrell 1988). It is not surprising that male body size was positively related to male call attractiveness, as body size is directly associated with the size of the vocal apparatus. However, because age, independent of size (SVL or mass), is also negatively correlated with call dominant frequency in C. ornatus, female preference for low dominant frequency also equates to choosing older males.

The dominant frequencies of attractive males were not skewed toward the low end of dominant frequencies exhibited by the chorus. Instead, females appear to choose the male possessing a call with the relatively lower dominant frequency available at the time and place that choice occurs. Therefore, male success in attracting females appears to be context dependent, based on competition at the time and place of calling, with the lowest dominant frequency in the part of the chorus proximate to the female most likely to succeed. This can occur if female $C$. ornatus are only able to detect calls with intensity greater or equal to that of the background chorus, as found in the green treefrog Hyla cinerea (Gerhardt and Klump 1987).

Calls made during courtship leading were significantly were distinguished by a characteristic drop in dominant frequency, while the other characteristics of the call were not altered. This concurs with the suggestion that relatively low call dominant frequency is a criterion for female mate choice (Forester and Lykens 1986). It also suggests an alternative explanation for why the dominant frequencies of attractive males were not skewed toward the low end of dominant frequencies exhibited by the chorus. If males are capable of altering their dominant frequency, then perhaps, they only do so to the extent necessary to outcompete their closest competitors on a given evening, thereby confounding general comparison with the population. Similar male-male competition involving the situation-dependent lowering of dominant frequencies is known from Blanchard's cricket frog Acris crepitans blanchardi (Wagner 1989). Relatedly, the lowering of the decibel level during the courtship call different from advertisement calls. Male courtship calls 
may have occurred because it conserved energy, or a quieter call may restrict the number of conspecifics or predators that would be aware of the pair's presence.

The path taken from the call site to the nest site was far more convoluted when males were accompanied by females. Furthermore, the level of convolution increased with closer proximity of the nest site to the call site. It appears that males need to engage the female in a minimum length of courtship-leading to increase the chances that the female will lay eggs in his nest or to gain information about the female's readiness to mate (Wells 1978). This would explain why males with nests less than $50 \mathrm{~cm}$ from their call site are leading females over a distance three to six times that is actually needed to reach the nest.

Although an increased path length may increase mating success, there was no direct relationship between the convolution of the path and male mating success, nor did females terminate courtship during this journey. The importance of the courtship behavior to male mating success or female mate choice is therefore unclear, especially as the behavior prolongs time and energy investment of both the male and female. Our results may indicate, however, that the males in our sample passed the threshold requirements for this component of mate choice as no females terminated courtship during this stage. Experimental shortening of the path length used by the male would be required to test this hypothesis.

The last stage of the female mate choice in C. ornatus occurs at the nest. Females chose nests with specific characteristics. Acceptable nests were deep, elongated, small-chambered, with mud or wood structures, and apparently offered a much more protected environment than did rejected nests. The preference of females for nests possessing these features suggests that these nest characteristics provide indirect fitness benefits (Reynolds and Gross 1990), possibly through increased protection from abiotic and biotic disturbances. Because it is likely that females would choose nests well suited to successful incubation, experimental manipulation of nest type is required to determine whether nest characteristics contribute directly to nest success.

Older males were more likely to possess nests with characteristics acceptable to females. It is possible that male $C$. ornatus construct or modify their nest chambers, as do other species of anurans (Duellman and Trueb 1994). In support of this scenario, mud nests disappear after males abandon them but maintain their structure as long as males are in residence (AF, personal observation). If males do construct or maintain nests, then increased mating success with age may be due to increased experience (Kokko and Lindström 1996) with regard to nest construction or maintenance. Age may also influence a male's ability to provide an acceptable nest via two alternative but not mutually exclusive scenarios. As male $C$. ornatus are strongly site-attached (Brooke et al. 2000), older males may have the opportunity to find more appropriate nest sites over time. Alternatively, old males, possessing greater conflict experience, may be better able to take over nest sites from young males (Howard 1978).
Another potential component of female mate choice at the nest is the importance of other females' eggs in the egg chamber. This is called mate choice copying, and it occurs when females show a preference for mated males (PruettJones and Pruett-Jones 1990). In C. ornatus, males may have obtained increased mating success not only due to the quality of their nests but also due to female choice for nests that already contained eggs. Experimental addition and removal of eggs in nests are needed to determine the role of nest quality versus the number of existing eggs in female decision making. Future studies involving a larger number of nests would allow for manipulations of egg numbers to determine whether females are influenced in their nest choice by the presence of eggs. It would also be of interest to determine whether the number of clutches or eggs in a nest influences hatching success.

There are several potential benefits of male $C$. ornatus remaining in the nest with the clutch. Males lunged at objects inserted into the nest (AF, personal observation). Other species that protect their nests from predation show similar behaviors (Kluge 1981 in Sullivan et al. 1995; Simon 1983; Townsend et al. 1984; Stewart and Rand 1991). In addition, the posture males assume over the eggs may increase clutch survival rates by preventing developmental abnormalities and/or reducing the adherence of fungal hyphae by moving the eggs. They also provide a protective layer that reduced the area of the clutch exposed to air. Egg predation, fungal infestation, and other unknown causes of mortality (possibly desiccation) all occurred in nests that were subsequently abandoned. It is unknown whether the eggs were abandoned due to mortality, or the mortality occurred after their abandonment. Male behavior during clutch attendance strongly suggests that clutch survival should be improved by their presence.

No components of male phenotype measured were related to the quality of paternal care. Neither nest attendance rates nor hatching success was related to SVL, mass, male condition, or age. It is possible, however, that aspects of male phenotype and their relationship to male parental care may only be apparent under predation pressure or during other events not observed.

Older males did not spend longer time attending eggs, and clutch survival rates were not related to the age of the attending male. Therefore, it is unclear whether females benefit from a better quality of parental care from choosing older males. However, the males used in this analysis were, of necessity, a chosen subset of males in the population, distinguished by their possession of attractive call characteristics and nests. Therefore, phenotypic variation among these males was reduced, possibly preventing us from detecting correlations between male phenotype and paternal care. This may explain why female choice of nests provided by older males is apparently not augmented by choice for improved parental care.

As there was no relationship between any male phenotypic character and male parental care, we cannot provide a mechanism for females to assess male parenting abilities. Instead females appear to base their final choice of 
oviposition site on the characteristics of the nest itself. It would be of interest, though, to determine whether male phenotype could at some future point be related to fertilization success rates, as in Ololygonrubra (Bourne 1993).

To conclude, this is the first study of an anuran mating system to find evidence suggesting the importance of male age, independent of size, as a female mate choice criterion. This study has also provided the first evidence that male age in an anuran is correlated to male call characteristics, independent of size. Previously, the importance of age as an influence on call characteristics was only known from studies of mammals and birds (Johnstone 1995). Our results and conclusions suggest that the importance of age as a mate choice criterion extends to amphibians. This will allow for increased across-taxa testing of theories linking the importance of increased age to female mate choice.

Acknowledgements We would like to thank Dr. S.J. Richards for research advice and the people of Paluma, Queensland, Australia, for welcoming this research. We also wish to thank three anonymous reviewers for helpful comments on an earlier draft of this paper. This study was funded by James Cook University and conducted in accordance with the laws and ethical guidelines of Australia.

\section{References}

Alatalo RV, Lundberg A, Glynn C (1986) Female pied flycatchers choose territory quality and not male characteristics. Nature 323:152-153

Alford RA (1999) RAMANOVA Version 1.48, School of tropical biology. James Cook University of North Queensland, Townsville

Arak A (1988) Callers and satellites in the natterjack toad: evolutionary stable decision rules. Anim Behav 36:416-432

Avery MI (1984) Lekking in birds: choice, competition and reproductive constraints. Ibis 126:177-187

Avisoft Bioacoustics (1999) Saslab Pro, Berlin

Backwell PRY, Passmore NI (1996) Time constraints and multiple choice criteria in the sampling behaviour and mate choice of the fiddler crab, Ucaannulipes. Behav Ecol Sociobiol 38:407-416

Balmford A, Rosser AM, Albon SD (1992) Correlates of female choice in resource-defending antelope. Behav Ecol Sociobiol $31: 107-114$

Barlow GW (1992) Is mating different in monogamous species? The midas cichlid fish as a case study. Am Zool 32:91-99

Bourne GR (1993) Proximate costs and benefits of mate acquisition at leks of the frog Ololygon rubra. Anim Behav 45:1051-1059

Bourne GR (1997) Reproductive behaviour of terrestrial breeding frogs Eleutherodactylus johnstonei in Guyana. J Herpetol 31 (2):221-229

Brooke PN, Alford RA, Schwarzkopf L (2000) Environmental and social factors influence chorusing behaviour in a tropical frog: examining various temporal and spatial scales. Behav Ecol Sociobiol 49(1):79-87

Clutton-Brock TH, Green D, Hiraiwa-Hasegawa M, Albon SD (1988) Passing the buck: resource defence, lek breeding and mate choice in fallow deer. Behav Ecol Sociobiol 23:281-286

Côté IM, Hunte W (1989) Male and female mate choice in the redlip blenny: why bigger is better. Anim Behav 38:78-88

Crump ML (1995) Parental care. In: Sullivan BK (ed) Amphibian biology, vol 2: Social behaviour. Surrey Beatty, Chipping Norton, pp 518-567

CYTEL Software Corporation (1999) StatXact-4, Version 4.0

Duellman WE, Trueb L (1994) Biology of amphibians. The John Hopkins University Press, Baltimore
Emlen ST, Oring LW (1977) Ecology, sexual selection, and the evolution of mating systems. Science 197:215-223

Forester DC (1979) The adaptiveness of parental care in Desmognathus ochrophaeus (Urodela: Plethodontidae). Copeia 1979:332-341

Forester DC (1984) Brooding behaviour by the mountain dusky salamander: can the female's presence reduce clutch desiccation? Herpetologica 40:105-109

Forester DC, Czarnowsky R (1985) Sexual selection in the spring peeper, Hyla crucifer (Amphibia, Anura): role of the advertisement call. Behaviour 92:112-128

Forester DC, Lykens DV (1986) Significance of satellite males in a population of spring peepers (Hyla crucifer). Copeia 1986 (3):719-724

Gerhardt HC (1991) Female mate choice in treefrogs: static and dynamic acoustic criteria. Anim Behav 42:615-635

Gerhardt HC, Klump GM (1987) Masking of acoustic signals by the chorus background noise in the green tree frog: a limitation on mate choice. Anim Behav 36:1247-1249

Gwynne DT (1984) Courtship feeding increases female reproductive success in bushcrickets. Nature 307:361-363

Halliday TR, Verrell PA (1988) Body size and age in amphibians and reptiles. J Herpetol 22:253-265

Heyer WR, Donnelly MA, McDiarmid RW, Hayek LC, Foster MS (1994) Measuring and monitoring biological diversity: standard methods for amphibians. Smithsonian Institution Press, Washington, DC

Howard RD (1978) The evolution of mating strategies in bullfrogs, Rana catesbeiana. Evolution 32(4):850-871

Johnstone RA (1995) Sexual selection, honest advertisement and the handicap principle: reviewing the evidence. Biol Rev 70:1-65

Jones JC, Reynolds JD (1999) The influence of oxygen stress on female choice for male nest structure in the common goby. Anim Behav 57:189-196

Kasuya E, Kobayashi T, Ootaki M (1997) Female preference for temporal features of vocalization in the Japanese treefrog, Rhacophorus arboreus. J Ethol 15:103-108

Kokko H (1997) Evolutionary stable strategies of age-dependent sexual advertisement. Behav Ecol Sociobiol 41:99-107

Kokko H, Lindström J (1996) Evolution of female preference for old mates. Proc R Soc Lond B Biol Sci 263:1533-1538

Lopez PT, Narins PM (1991) Mate choice in the neotropical frog, Eleutherodactylus coqui. Anim Behav 41:757-777

Lykens DV, Forester DC (1987) Age structure in the spring peeper: do males advertise longevity. Herpetologica 43:216-223

McDonald K (1991) Frogs. In: Nix HA, Switzer MA (eds) Rainforest animals: atlas of vertebrates endemic to Australia's wet tropics. Australian National Parks and Wildlife Service, Canberra, pp 83-104

Morris MR (1989) Female choice of large males in the treefrog Hyla chrysoscelis: the importance of identifying the scale of choice. Behav Ecol Sociobiol 25:275-281

Morris MR, Yoon S (1989) A mechanism for female choice of large males in the treefrog Hyla chrysoscelis. Behav Ecol Sociobiol 25:65-71

Orlov N (1997) Breeding behavior and nest construction in a Vietnam frog related to Rana blythi. Copeia 1997(2):464-465

Passmore NI, Bishop PJ, Caithness N (1992) Calling behaviour influences mating success in male painted reed frogs, Hyperolius marmoratus. Ethology 92:227-241

Platz JE, Lathrop A (1993) Rana subaquavocalis, a remarkable new species of leopard frog (Rana pipiens complex) from southeastern Arizona that calls underwater. J Herpetol 27:154-162

Pruett-Jones SG, Pruett-Jones MA (1990) Sexual selection through female choice in Lawes' Parotia, a lek mating bird of paradise. Evolution 44:486-501

Reynolds JD, Gross MR (1990) Costs and benefits of female mate choice: is there a lek paradox? Am Nat 136:230-243

Robertson JGM (1986) Female choice, male strategies and the role of vocalizations in the Australian frog Uperoleia rugosa. Anim Behav 34(3):773-784 
Robertson JGM (1990) Female choice increases fertilization success in the Australian frog, Uperoleia laevigata. Anim Behav 39:639-645

Ryan MJ (1980) Female mate choice in a neotropical frog. Science 209:523-525

Ryan MJ (1983) Sexual selection and communication in a neotropical frog, Physalaemus pustulosus. Evolution 37 (2):261-272

Ryan MJ (1985) The Tungara frog. University of Chicago Press, Chicago

Simon MP (1983) The ecology of parental care in a terrestrial breeding frog from New Guinea. Behav Ecol Sociobiol 14:6167

SPSS Inc. (1997) Release 8.0.0 for Windows

Stewart MM, Rand AS (1991) Vocalizations and the defence of retreat sites by male and female frogs, Eleutherodactylus coqui. Copeia 1991:1013-1024

Sullivan BK (1983) Sexual selection in Woodhouse's toad (Bufo woodhousei) II. Female choice. Anim Behav 31:1011-1017

Sullivan BK, Ryan MJ, Verrell PA (1995) Female choice and mating system structure. In: Sullivan BK (ed) Amphibian biology, vol 2: Social behaviour. Surrey Beatty, Chipping Norton, pp 469517
Summers K (1992) Mating strategies in two species of dart-poison frogs: a comparative study. Anim Behav 43:907-919

Townsend DS, Stewart MM (1986) Courtship and mating behavior of a Puerto Rican frog, Eleutherodactylus coqui. Herpetologica 42:165-170

Townsend DS, Stewart MM (1994) Reproductive ecology of the Puerto Rican frog Eleutherodactylus coqui. J Herpetol 28 (1):34-40

Townsend DS, Stewart MM, Pough FH (1984) Male parental care and its adaptive significance in a neotropical frog. Anim Behav $32: 421-431$

Wagner WE Jr (1989) Fighting, assessment, and frequency alteration in Blanchard's cricket frog. Behav Ecol Sociobiol 25:429-436

Wells KD (1978) Courtship and parental behaviour in a Panamanian poison-arrow frog (Dendrobates auratus). Herpetologica 34 (2): $148-155$

Zweifel RG (1985) Australian frogs of the family Microhylidae. Bull Am Mus Nat Hist 182:265-388 